\title{
Calcium intake and osteoporosis: the influence of calcium intake from dairy products on hip bone mineral density and fracture incidence - a population-based study in women over 55 years of age
}

\author{
Dariusz Włodarek 1,*, Dominika Głąbska ${ }^{1}$, Aleksandra Kołota ${ }^{2}$, Piotr Adamczyk ${ }^{3}$, \\ Aleksandra Czekajło ${ }^{4}$, Władysław Grzeszczak ${ }^{5}$, Bogna Drozdzowska ${ }^{6}$ and \\ Wojciech Pluskiewicz ${ }^{7}$ \\ ${ }^{1}$ Department of Dietetics, Faculty of Human Nutrition and Consumer Sciences, Warsaw University of Life \\ Sciences-SGGW, 159c Nowoursynowska Street, 02-776 Warsaw, Poland: ${ }^{2}$ Chair of Nutritional Physiology, \\ Department of Dietetics, Faculty of Human Nutrition and Consumer Sciences, Warsaw University of Life \\ Sciences, Warsaw, Poland: ${ }^{3}$ Department and Clinic of Pediatrics, Medical University of Silesia, Katowice, \\ Poland: ${ }^{4}$ Department of Nephrology, Regional Hospital in Racibórz, Racibórz, Poland: ${ }^{5}$ Department and Clinic \\ of Internal Diseases, Diabetology and Nephrology, Medical University of Silesia, Katowice, Poland: \\ ${ }^{6}$ Department of Pathomorphology, Medical University of Silesia, Katowice, Poland: ${ }^{7}$ Metabolic Bone \\ Diseases Unit, Department and Clinic of Internal Diseases, Diabetology and Nephrology, Medical \\ University of Silesia, Katowice, Poland
}

Submitted 19 June 2012: Final revision received 30 October 2012: Accepted 12 November 2012: First published online 10 December 2012

\begin{abstract}
Objective: The incidence of osteoporosis increases with age and is most frequently observed in postmenopausal women. The objective of the present populationbased cohort study was to assess the influence of Ca intake from dairy sources on hip bone mineral density and hip fracture incidence in a group of Polish women over 55 years of age.

Design: The main outcome measures included: bone mineral density, the number of previous fractures and the reported $\mathrm{Ca}$ intake from dairy sources, assessed by a diet questionnaire.

Setting: The RAC-OST-POL Study was conducted in the District of Raciborz in the south of Poland.

Subjects: The study was carried out in a group of 625 women, randomly recruited from the general population of women aged $>55$ years.

Results: Median Ca intake from dairy products was lower in the group of women with femoral neck T-score $\leq-2.5$ than in the group with T-score $>-2.5$ (275 $v$. $383 \mathrm{mg} / \mathrm{d} ; P=0 \cdot 0019)$. For total hip score, the difference was close to borderline significance $(P=0 \cdot 0698)$. Median Ca intake from dairy products was lower in the group of women with previous fractures than in those without fracture history (336 v. 395 mg/d; $P=0.0254$ ). The main dairy source of $\mathrm{Ca}$ in the analysed group included milk drinks, rennet cheese and milk.

Conclusions: Higher dairy $\mathrm{Ca}$ intake is recommended, since a number of the women analysed were unable to satisfy their $\mathrm{Ca}$ requirement exclusively from their diet.
\end{abstract}

Keywords

Osteoporosis

Women

Calcium

Dairy products
Osteoporosis is a skeletal disease associated with low bone mass, microarchitectural deterioration of bone tissue and, as a consequence, increased bone fragility and susceptibility to fracture ${ }^{(1)}$. The incidence of osteoporosis increases with age and is most frequently observed in postmenopausal women, as bone tissue loss and remodelling are accelerated by decreased ovarian oestrogen levels associated with menopause ${ }^{(2)}$. Osteoporotic bone fractures may be particularly devastating in the case of elderly women. Fracture prevention is one of the key goals of osteoporosis therapy in postmenopausal women, with targets to inhibit bone loss processes, maintain proper bone strength, and minimise or eliminate the factors contributing to slips or falls ${ }^{(3)}$.

The relationship between $\mathrm{Ca}$ intake and bone mineral density (BMD) is a widely analysed issue; higher Ca intake is associated with increased bone density in children ${ }^{(4)}$, as well as higher bone mass ${ }^{(5)}$, reduced risk of osteoporosis ${ }^{(6)}$ 
and lower fracture risks ${ }^{(7)}$ in adults and the elderly. The above-mentioned association is very complex and some authors emphasise the role of other factors, such as environmental factors for example, while doubting any strong correlation with $\mathrm{Ca}^{(8,9)}$. Simultaneously, besides gender and age, body mass is the third important element which influences the risk of osteoporosis ${ }^{(10)}$, while being also associated with $\mathrm{Ca}$ intake ${ }^{(11,12)}$.

The most important sources of $\mathrm{Ca}$ are dairy products, providing over $60 \%$ of daily Ca intake in women's diets $^{(13,14)}$ and even $74 \%$ in some Polish studies ${ }^{(15)}$. Simultaneously, they are at least as efficacious as Ca supplements in osteoporosis prevention ${ }^{(16)}$.

It was hypothesised that $\mathrm{Ca}$ intake from dairy sources will be associated with BMD in women over 55 years of age. The objective of the present population-based cohort study was to assess the influence of Ca intake from dairy sources on hip BMD and hip fracture incidence in a group of Polish women aged $>55$ years.

\section{Methods}

The RAC-OST-POL study was carried out in a group of Polish women aged $>55$ years, randomly recruited from the general population of women over 55 years of age in the District of Raciborz in the south of Poland. The total number of eligible women inhabiting the region at the time of enrolment was 17500, from whom 1750 were randomly selected and invited by regular mail to participate in the study. A blind list of women, selected for the study, was provided by the local government and each woman was assigned a number without showing her name. A group of 625 women responded positively to the invitation and declared their intention to take part in the study, which was performed in May 2010. Among these women, six were still menstruating. All 625 participants were submitted to the study protocol, including BMD measurements and an FFQ to assess Ca intake. Body weight and height were measured with a standard medical balance and used to calculate BMI $\left(\mathrm{kg} / \mathrm{m}^{2}\right)$. The study complied with the guidelines of the Declaration of Helsinki and all procedures involving human subjects were approved by the Ethics Committee of the Medical University of Silesia, Katowice, Poland. A written informed consent was obtained from all participants. The study group was described in a previous paper ${ }^{(17)}$.

Osteoporosis has been operationally defined on the basis of BMD assessment. According to the WHO criteria, osteoporosis is defined as a BMD level that lies $2.5 \mathrm{sD}$ or more below the average value for young healthy women (T-score of $\leq-2 \cdot 5)^{(18)}$. The skeletal status was assessed by a Lunar DPX bone densitometer (GE Healthcare, Waukesha, WI, USA), assessing femoral neck and total hip bone density. Densitometric variables are presented as $\operatorname{BMD}\left(\mathrm{g} / \mathrm{cm}^{2}\right)$ and T-score. All measurements were performed by one operator. The $\mathrm{CV}$ for measurements (calculated on the basis of fifty measurements - two for each participant with reposition) was $1.6 \%$ for femoral neck and $0 \cdot 82 \%$ for total hip. Participants were queried about previous fractures of non-traumatic origin, e.g. caused by a fall from standing height or less; since no radiograms were obtained, some spine fractures might have been missed.

Participants were asked questions from the applied FFQ to assess their Ca intake from dairy products; they were asked by a dietitian about the frequency of consumption of forty-nine dairy products most common in Poland (e.g. milk, yoghurt, other milk beverages, rennet cheese, cottage cheese) and of meals containing dairy products, as well as typical portion sizes. Ca intake from a particular product was estimated by the following formula: Ca intake $(\mathrm{mg})=$ typical portion size $(\mathrm{g}) \times \mathrm{Ca}$ content $(\mathrm{mg} / \mathrm{g})$. The FFQ results were analysed using the Dietetyk 2 software package (the Polish dietetic software) and the Polish database of nutritional values of food products $^{(19)}$. The use of an FFQ to assess Ca intake is a commonly accepted and widely applied method, taking into account specified sources of $\mathrm{Ca}$ in the diet, mainly dairy products ${ }^{(13,20-23)}$. The standard error of the $\mathrm{Ca}$ estimate for the FFQ administered (calculated on the basis of two measurements for fifty participants with repetition during the period of 6 weeks) was $180 \mathrm{mg}$, while the median difference for the two estimations of daily $\mathrm{Ca}$ intake was $12 \%$. A similar questionnaire, taking into account similar groups of products and applied to assess Ca intake in the Polish population, was also characterised by high sensitivity ${ }^{(24)}$.

Data are presented as means and standard deviations, along with minimum, maximum and median values. The distribution of the analysed factors was verified using the Shapiro-Wilk test, while the Spearman correlation coefficient was used to characterise relationships among the analysed factors and the Mann-Whitney $U$ test was used to analyse differences between groups.

An additional statistical analysis was performed in order to confirm that the analysed population might be treated as a representative sub-sample. It was verified whether the mean age in the analysed sub-population matched the mean age in the general population. The two-sided level of significance $P \leq 0.05$ was accepted to define the significance of correlations. Statistical analysis was carried out using the Statistica software version $8 \cdot 0$.

\section{Results}

Table 1 presents the characteristic features of the participants: age, body weight, body height and BMI. According to the 2010 Statistical Yearbook, the general population of women over 55 years of age in Poland comprises the following age subgroups: $29 \cdot 8 \%$ aged $55-59$ years, $14 \cdot 3 \%$ 
Table 1 Characteristic features of the participants: Polish women $(n 625)$ aged $>55$ years, RAC-OST-POL Study, May 2010

\begin{tabular}{lrrrrr}
\hline & Mean & SD & Median & Minimum & Maximum \\
\hline Age (years) & $66 \cdot 4$ & $7 \cdot 8$ & $65 \cdot 7^{*}$ & $55 \cdot 0$ & $92 \cdot 2$ \\
Body height $(\mathrm{cm})$ & $155 \cdot 4$ & $6 \cdot 0$ & $156 \cdot 0^{*}$ & $136 \cdot 0$ & $175 \cdot 0$ \\
Body weight $(\mathrm{kg})$ & $75 \cdot 5$ & $14 \cdot 2$ & $75 \cdot 0^{*}$ & $39 \cdot 0$ & $125 \cdot 0$ \\
BMI $\left(\mathrm{kg} / \mathrm{m}^{2}\right)$ & $31 \cdot 2$ & $5 \cdot 5$ & $30 \cdot 8^{*}$ & $15 \cdot 4$ & $53 \cdot 1$ \\
\hline
\end{tabular}

*Variable was not normally distributed (verified by the Shapiro-Wilk test; $P \leq 0 \cdot 05$ ).

Table 2 Dairy calcium intake $(\mathrm{mg} / \mathrm{d})$ according to femoral neck and total hip bone mineral density T-scores: Polish women ( $n$ 625) aged $>55$ years, RAC-OST-POL Study, May 2010

\begin{tabular}{|c|c|c|c|c|c|c|c|c|}
\hline & \multirow[b]{2}{*}{ T-score } & \multirow[b]{2}{*}{$n$} & \multicolumn{5}{|c|}{ Dairy Ca intake $(\mathrm{mg} / \mathrm{d})$} & \multirow[b]{2}{*}{$P$ value* } \\
\hline & & & Mean & SD & Median & Minimum & Maximum & \\
\hline \multirow[t]{2}{*}{ Femoral neck } & $\leq-2 \cdot 5$ & 59 & $360 \cdot 4$ & $226 \cdot 1$ & $274 \cdot 9+$ & $3 \cdot 6$ & $1915 \cdot 1$ & \multirow[t]{2}{*}{$0 \cdot 0019$} \\
\hline & $>-2.5$ & 559 & $431 \cdot 1$ & $263 \cdot 1$ & $383 \cdot 0 \dagger$ & $15 \cdot 5$ & $1922 \cdot 9$ & \\
\hline \multirow[t]{2}{*}{ Total hip } & $\leq-2 \cdot 5$ & 23 & $311 \cdot 1$ & $202 \cdot 2$ & $239 \cdot 2 t$ & $99 \cdot 0$ & $770 \cdot 3$ & \multirow[t]{2}{*}{0.0698} \\
\hline & $>-2.5$ & 595 & $428 \cdot 0$ & $271 \cdot 8$ & $374 \cdot 0 t$ & $3 \cdot 6$ & $1922 \cdot 9$ & \\
\hline
\end{tabular}

*Differences assessed by the Mann-Whitney $U$ test.

+ Variable was not normally distributed (verified by the Shapiro-Wilk test; $P \leq 0.05$ )

Table 3 Dairy calcium intake (mg/d) according to fracture status: Polish women $(n 625)$ aged $>55$ years, RAC-OSTPOL Study, May 2010

\begin{tabular}{lccccccr}
\hline & \multicolumn{7}{c}{ Dairy Ca intake $(\mathrm{mg} / \mathrm{d})$} \\
\cline { 2 - 6 } Fracture status & $n$ & Mean & SD & Median & Minimum & Maximum & $P$ value $^{*}$ \\
\hline Fractures & 176 & 390.5 & 256.5 & $336.4 \dagger$ & 3.6 & 1922.9 & 0.0254 \\
No fractures & 450 & 438.1 & 273.6 & $395 \cdot 4 \dagger$ & 15.5 & 1915.1 & \\
\hline
\end{tabular}

*Differences assessed by the Mann-Whitney $U$ test.

+Variable was not normally distributed (verified by the Shapiro-Wilk test; $P \leq 0.05$ ).

Table 4 Calcium intake $(\mathrm{mg} / \mathrm{d})$ from dairy sources: Polish women $(n 625)$ aged $>55$ years, RAC-OST-POL Study, May 2010

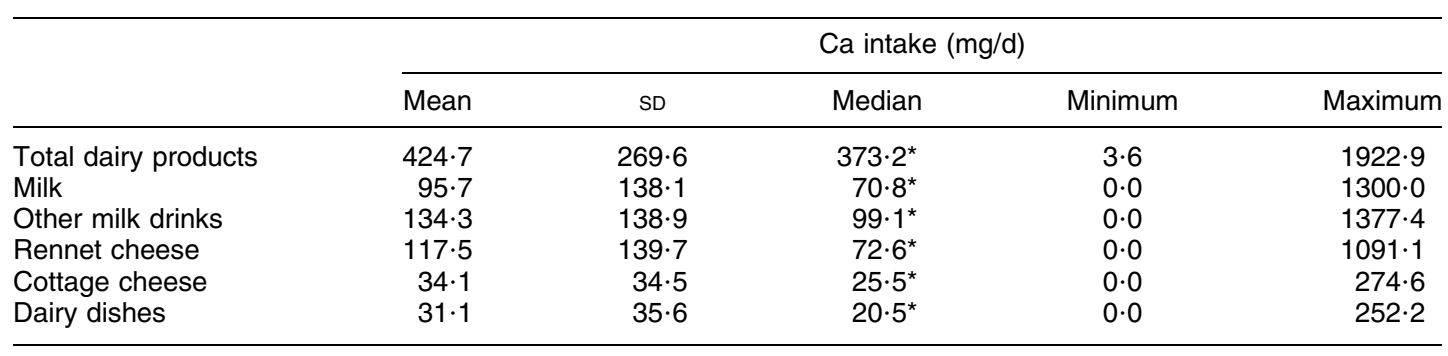

*Variable was not normally distributed (verified by the Shapiro-Wilk test; $P \leq 0.05$ ).

aged 60-64 years and 55.9\% aged 65 years and older ${ }^{(25)}$. These age subgroups accounted for respectively $27 \cdot 0 \%$, $19 \cdot 8 \%$ and $53 \cdot 2 \%$ of the women in the present study. The $\chi^{2}$ test performed for the subgroup aged 60-64 years revealed a significant difference between typical and observed numerical strength in the analysed group. A significant correlation was found between age and BMI values $(P=0 \cdot 0017 ; r=0 \cdot 12)$.

Dairy Ca intakes of the women, grouped according to femoral neck and total hip T-scores $>-2.5$ or $\leq-2 \cdot 5$, are presented in Table 2. Ca intake from dairy products was lower in the group of women with femoral neck T-scores $\leq-2.5$ than in the group with T-scores $>-2.5$
$(P=0 \cdot 0019)$. For the total hip scores, the difference was borderline significant $(P=0 \cdot 0698)$.

Table 3 presents the associations between dairy $\mathrm{Ca}$ intake and fractures. Ca intake from dairy products was lower in the group of women with previous fractures than in those without fracture history $(P=0.0254)$.

$\mathrm{Ca}$ intake from various dairy sources is presented in Table 4. The median $\mathrm{Ca}$ intake from total dairy products was $373.2 \mathrm{mg} / \mathrm{d}$ in the analysed group; however with a considerable variability among particular individuals, ranging from $3.6 \mathrm{mg} / \mathrm{d}$ to $1922.9 \mathrm{mg} / \mathrm{d}$. Other milk drinks (i.e. drinks other than milk, such as yoghurt, kefir, buttermilk) were the main dairy source of $\mathrm{Ca}$, providing a 
Table 5 Correlations of age and BMI with calcium intake from dairy sources: Polish women $(n$ 625) aged $>55$ years, RAC-OST-POL Study, May 2010

\begin{tabular}{llrlrr}
\hline & \multicolumn{2}{c}{ Age } & & \multicolumn{2}{c}{ BMI } \\
\cline { 2 - 3 } \cline { 5 - 6 } \cline { 5 - 6 } & $P$ value & $r$ & & $P$ value & \multicolumn{1}{c}{$r$} \\
\hline Total dairy products & $0.0000^{*}$ & -0.19 & & 0.4192 & -0.03 \\
Milk & 0.1980 & -0.05 & & 0.2066 & 0.05 \\
Other milk drinks & $0.0002^{*}$ & -0.15 & & 0.5740 & 0.02 \\
Rennet cheese & $0.0001^{*}$ & -0.16 & & 0.7871 & -0.01 \\
Cottage cheese & $0.0000^{*}$ & -0.19 & & $0.0115^{\star}$ & -0.10 \\
Dairy dishes & $0.0008^{*}$ & 0.13 & 0.3257 & 0.04 \\
\hline
\end{tabular}

*Significant correlations (assessed by the Spearman correlation coefficient; $P \leq 0.05)$.

Table 6 Correlations between calcium intake from dairy sources and femoral neck and total hip bone mineral density (BMD): Polish women $(n 625)$ aged $>55$ years, RAC-OST-POL Study, May 2010

\begin{tabular}{|c|c|c|c|c|}
\hline & \multicolumn{2}{|c|}{ BMD-femoral neck } & \multicolumn{2}{|c|}{ BMD-total hip } \\
\hline & $P$ value & $r$ & $P$ value & $r$ \\
\hline Total dairy products & $0.0048^{*}$ & $0 \cdot 11$ & $0 \cdot 0198^{*}$ & 0.09 \\
\hline Milk & $0.0039^{*}$ & $0 \cdot 12$ & $0.0361^{*}$ & 0.08 \\
\hline Other milk drinks & $0.0001^{*}$ & $0 \cdot 15$ & $0.0001^{*}$ & $0 \cdot 15$ \\
\hline Rennet cheese & 0.2799 & 0.04 & 0.2870 & 0.04 \\
\hline Cottage cheese & 0.1203 & 0.06 & 0.5519 & 0.02 \\
\hline Dairy dishes & 0.1470 & -0.06 & $0.0057^{\star}$ & -0.11 \\
\hline
\end{tabular}

*Significant correlations (assessed by the Spearman correlation coefficient; $P \leq 0.05)$.

median of $99 \cdot 1 \mathrm{mg} \mathrm{Ca} / \mathrm{d}$. Important sources of $\mathrm{Ca}$ included rennet cheese (median $72.6 \mathrm{mg} / \mathrm{d}$ ) and milk (median $70.8 \mathrm{mg} / \mathrm{d}$ ). The other analysed sources of $\mathrm{Ca}$ included cottage cheese, dairy dishes and other products.

The correlations of age and BMI with $\mathrm{Ca}$ intake from various dairy sources are presented in Table 5. In the case of older individuals, a lower intake of Ca was observed, both from total dairy products and particular dairy products groups (including milk, other milk drinks, cottage and rennet cheese), while a higher intake of $\mathrm{Ca}$ from dairy dishes was confirmed. BMI values were inversely correlated with $\mathrm{Ca}$ intake levels from cottage cheese only.

Table 6 presents correlations between $\mathrm{Ca}$ intake from various dairy sources and measured BMD values. Positive correlations between femoral neck and total hip BMD were observed for total dairy $\mathrm{Ca}$ intake as well as $\mathrm{Ca}$ intake from milk and other milk drinks, while a negative correlation was found between total hip BMD values and Ca intake from dairy dishes.

\section{Discussion}

The present data were obtained from research carried out in a group of Polish women aged $>55$ years, analysing their dietary $\mathrm{Ca}$ intake from dairy products and its association with osteoporosis. The correlation between dietary $\mathrm{Ca}$ intake and osteoporosis development arouses a great deal of controversy, as Ca intake is not the only factor affecting $\mathrm{BMD}^{(9)}$, but remains a vital issue that is evaluated intensively in various countries ${ }^{(26-30)}$.

The group of women analysed in the present study was characterised by excessive body mass, with a median BMI of $30 \cdot 84 \mathrm{~kg} / \mathrm{m}^{2}$. The high BMI values in these women are congruent with BMI levels observed in osteoporosis studies conducted in Europe ${ }^{(26,27)}$. Increased BMI may be associated with bone mineral $\operatorname{loss}^{(31)}$ and during weight reduction overweight postmenopausal women are also more susceptible to bone loss, even if they are characterised by daily Ca intake of $1000 \mathrm{mg}^{(32)}$.

Femoral neck T-score is the main indicator of osteoporosis in BMD assessment ${ }^{(18)}$, with fractures being the most adverse effect of the disease ${ }^{(33)}$. In the present study, women with either lower femoral neck T-scores or previous fractures were characterised by lower dairy Ca intake. Other reports indicate that postmenopausal women with higher intakes of dairy products are also characterised by higher lumbar BMD values ${ }^{(10)}$. Some researchers have emphasised a strong negative correlation between $\mathrm{Ca}$ intake and hip fracture incidence among women ${ }^{(34)}$, as well as a correlation between $\mathrm{Ca}$ intake and broadband ultrasound attenuation $Z$-score in elderly women ${ }^{(35)}$. However, other studies of $\mathrm{Ca}$ intake and osteoporosis indicated associations between $\mathrm{Ca}$ intake and BMD to be rather contradictory. Some researchers claim that, even if a certain influence of $\mathrm{Ca}$ intake on bone mass improvement is observed, neither $\mathrm{Ca}$ nor vitamin D supplementation demonstrates any short-term effect on fracture risk ${ }^{(6)}$; thus coming to the conclusion that no correlation exists between $\mathrm{Ca}$ intake and fracture incidence ${ }^{(28)}$.

Dairy $\mathrm{Ca}$ intake may be perceived as a strong predictor of total $\mathrm{Ca}$ intake, as $\mathrm{Ca}$ intake from products other than dairy products is fairly constant. The results of other authors indicate that dairy products provide over $60 \%$ of daily $\mathrm{Ca}$ intake in women's diets; in a group characterised by Ca intake of about $800 \mathrm{mg} / \mathrm{d}$ the contribution from dairy products was about $62 \%$, while in group characterised by Ca intake of about $900 \mathrm{mg} / \mathrm{d}$ the contribution amounted to about $84 \%^{(13)}$. As the daily $\mathrm{Ca}$ intake from non-dairy products remains at a fairly stable level, a higher total daily Ca intake suggests a higher contribution of Ca from dairy products in the diet. The total $\mathrm{Ca}$ intake of the women in the present study may be estimated as the sum of $\mathrm{Ca}$ intakes from all products in the FFQ and about $250 \mathrm{mg}$ Ca from products other than dairy products. Thus, in the present group of Polish women, Ca intake can be estimated at the level of about $675 \mathrm{mg} / \mathrm{d}$. In other research conducted in postmenopausal women in Poland, the total Ca intake was similar - over $600 \mathrm{mg}$ daily ${ }^{(36)}$. The latter study, performed in nine European countries, indicated that Polish women are characterised by low Ca intake compared with women in the other countries evaluated $^{(36)}$. Ca intake in non-European populations was lower than in Poland - below $600 \mathrm{mg} / \mathrm{d}^{(37-39)}$. The recommended daily $\mathrm{Ca}$ intake for postmenopausal women 
is $1000-1500 \mathrm{mg}$, depending on age and recommending institution $^{(40)}$. As a result, a number of women in the present study were unable to satisfy their Ca requirement exclusively from their diet.

The present women had lower intakes of Ca from milk and milk drinks, as well as from cheeses and other products, as compared with the results of other studies ${ }^{(13)}$. The proportion of dairy products as sources of Ca was also different. In the study by Poliquin et al. ${ }^{(14)}$ the proportion of Ca from milk to Ca from other dairy products was about $3 \cdot 2: 4$ and in the study by Fardellone et $a l^{(26)}$ it was about $1 \cdot 8: 4$, whereas the proportion was $0 \cdot 7: 4$ in the present study. Simultaneously, Gonelli et al. ${ }^{(13)}$ found the proportion of Ca from milk and milk drinks to $\mathrm{Ca}$ from cheeses and other dairy products to be about $3: 4$, while this proportion was $5 \cdot 5: 4$ in our study. Therefore it may be concluded that while milk consumption was low in the present study group, the consumption of other milk drinks was fairly high in comparison with the results from other research.

The strong effect of age on Ca intake we observed is also reported by other researchers ${ }^{(26,37,39)}$. According to other authors, the daily $\mathrm{Ca}$ intake of postmenopausal women is significantly lower than that of premenopausal women ${ }^{(39)}$ and the proportion of women with low $\mathrm{Ca}$ intake rises with age $^{(26,37)}$. However, the character of the relationship is not obvious, as other authors report lower $\mathrm{Ca}$ inadequacy in women above 75 years of age ${ }^{(36)}$, probably associated with higher intake of Ca supplements ${ }^{(14)}$.

In the present study it can be concluded that the lower $\mathrm{Ca}$ intake observed in the case of older women can be attributed to lower consumption of dairy products, probably as a result of changing nutritional habits. Simultaneously, milk consumption remains stable, independently of age, while the consumption of dairy dishes is higher, without any major impact on the total dairy Ca intake. With age, everyday activities such as preparing meals become more difficult ${ }^{(41)}$ and chewing ability also decreases $^{(42)}$. So, the above-mentioned higher consumption of dairy dishes may probably result from the fact that dairy dishes are easy to prepare and eat.

In the research of Zhong et al. ${ }^{(28)}$, a close to significant association was observed between $\mathrm{Ca}$ intake and $\mathrm{BMI}$ : postmenopausal women with higher BMI values reported lower Ca intake. No such correlation was observed in our study group. The only correlation we observed, that between cottage cheese consumption and BMI, could have been attributed to the general observation that individuals with lower BMI consume more cottage cheese, also confirmed by other researchers ${ }^{(43)}$.

In the present group of females, correlations were observed between $\mathrm{Ca}$ intake from various dairy sources and BMD that corresponded to the results of other authors, claiming similar correlations between $\mathrm{Ca}$ intake and $\operatorname{BMD}^{(39,44,45)}$.

In contrast, the observed negative correlation between Ca intake from dairy dishes and total hip BMD score is rather difficult to explain. Only the fact indicated previously, that dairy dishes are generally easier to prepare and to eat and may be more often chosen by elderly people, may provide an explanation. The positive correlation between dairy $\mathrm{Ca}$ intake and BMD in the case of $\mathrm{Ca}$ from milk and other milk drinks, but not for Ca from rennet cheese and cottage cheese, may be associated with lactose. Lactose is contained in milk and other milk drinks, being a factor promoting Ca absorption ${ }^{(46)}$. The content of lactose in milk and other milk drinks is significantly higher than in either rennet cheese or cottage cheese; according to the Polish food composition database, the lactose content is $4 \cdot 6-4 \cdot 9 \mathrm{~g} / 100 \mathrm{~g}$ and $4 \cdot 1-5 \cdot 0 \mathrm{~g} / 100 \mathrm{~g}$ for cow's milk and other milk drinks, as opposed to $0 \cdot 1-1 \cdot 0 \mathrm{~g} / 100 \mathrm{~g}$ and $1 \cdot 0-3 \cdot 3 \mathrm{~g} / 100 \mathrm{~g}$ for rennet cheese and cottage cheese, respectively ${ }^{(19)}$. So, it may be concluded that BMD is correlated not only with Ca from dairy products but with $\mathrm{Ca}$ intake from lactose-containing dairy products, where lactose improves $\mathrm{Ca}$ absorption.

One of the factors that influences Ca metabolism in the human body, and as a consequence reduces the risk of osteoporosis, is vitamin $\mathrm{D}_{3}$. In the present study, neither vitamin D intake nor its serum level was assessed. This may be a limitation of the study, but nevertheless the proper intake of $\mathrm{Ca}$ is the main dietary factor influencing bone density, and in the research of other authors a similar attitude is chosen ${ }^{(10,47)}$. Other potential limitations of our study may be associated with the fact that only $36 \%$ of invited women participated and that BMD was measured at the hip only and spine radiograms were not available, thus some spine fractures might not have been taken into account.

\section{Conclusions}

In the present group of Polish women above 55 years of age, it may be concluded that lower BMD (femoral neck T-score $\leq-2 \cdot 5)$ and previous fractures were associated with lower reported dairy $\mathrm{Ca}$ intake. Due to the insufficient consumption of dairy products, a number of women were unable to satisfy their Ca requirement exclusively from their diet. The main dairy sources of $\mathrm{Ca}$ in the analysed group included milk, other milk drinks and rennet cheese. It is therefore important to recommend the consumption of dairy products with lactose, a Caabsorption improving factor, such as milk and milk drinks, to improve BMD and reduce fracture risks in the population of postmenopausal women with osteoporosis.

\section{Acknowledgements}

Sources of funding: This research received no specific grant from any funding agency in the public, commercial or nonfor-profit sectors. Conflicts of interest: The authors have no conflicts of interest to declare. Authors' contributions: D.W. and W.P. designed study; D.W., D.G., A.K., P.A., A.C., W.G., 
B.D. and W.P. conducted the research; D.W., D.G. and A.K. analysed the data and performed the statistical analysis; D.W. and D.G. wrote the paper; D.W. had primary responsibility for final content.

\section{References}

1. Harvey N, Dennison E \& Cooper C (2008) Epidemiology of osteoporotic fracture. In Primer on the Metabolic Bone Diseases and Disorders of Mineral Metabolism, 7th ed., pp. 198-203 [MJ Favus, editor]. Washington, DC: American Society for Bone and Mineral Research.

2. North American Menopause Society (2006) The role of calcium in peri- and postmenopausal women: 2006 position statement of the North American Menopause Society. Menopause 13, 862-877.

3. North American Menopause Society (2002) Management of postmenopausal osteoporosis: position statement of the North American Menopause Society. Menopause 9, 84-101.

4. Wosje KS \& Specker BL (2000) Role of calcium in bone health during childhood. Nutr Rev 58, 253-268.

5. Nieves JW, Golden AL, Siris E et al. (1995) Teenage and current calcium intake are related to bone mineral density of the hip and forearm in women aged 30-39 years. $A m J$ Epidemiol 141, 342-351.

6. Nieves JW, Barrett-Connor E, Siris ES et al. (2008) Calcium and vitamin D intake influence bone mass, but not shortterm fracture risk, in Caucasian postmenopausal women from the National Osteoporosis Risk Assessment (NORA) study. Osteoporos Int 19, 673-679.

7. Heaney RP (1992) Calcium in the prevention and treatment of osteoporosis. J Intern Med 231, 169-180.

8. Badurski J, Dobreńko A, Nowak N et al. (2008) Bialystok osteoporosis study-2: epidemiology of osteoporotic fractures and 10 year fracture risk assessment in population of women in Bialystok region by FRAX ${ }^{\mathrm{TM}}-\mathrm{WHO}$ algorithm. Reumatol 46, 72-79.

9. Badurski J, Jeziernicka E, Dobreńko A et al. (2011) The characteristics of osteoporotic fractures in the region of Bialystok (BOS-2). The application of the WHO algorithm, FRAX $囚 B M I$ and FRAX $囚 B M D$ assessment tools to determine patients for intervention. Pol J Endocrinol 62, 290-298.

10. Varenna M, Binelli L, Casari S et al. (2007) Effects of dietary calcium intake on body weight and prevalence of osteoporosis in early postmenopausal women. Am J Clin Nutr 86, 639-644.

11. Bueno MB, Cesar CLG, Martini LA et al. (2008) Dietary calcium intake and overweight: an epidemiologic view. Nutrition 24, 1110-1115.

12. Dicker D, Belnic Y, Goldsmith R et al. (2008) Relationship between dietary calcium intake, body mass index, and waist circumference in MABAT - the Israeli National Health and Nutrition Study. Isr Med Assoc J 10, 512-515.

13. Gonnelli S, Rossi S, Montomoli M et al. (2009) Accuracy of different reduced versions of a validated food-frequency questionnaire in Italian men and women. Calcif Tissue Int 85, 221-227.

14. Poliquin S, Joseph L \& Gray-Donald K (2009) Calcium and vitamin D intakes in an adult Canadian population. Can J Diet Pract Res 70, 21-27.

15. Wądołowska L, Pabjan K, Słowińska MA et al. (2010) Bone mineral density and consumption of calcium, calcium-fortified food and calcium supplements by women - a short report. Pol J Food Nutr Sci 60, 183-187.

16. Heaney RP (2000) Calcium, dairy products and osteoporosis. J Am Coll Nutr 19, 2 Suppl., S83-S99.

17. Pluskiewicz W, Adamczyk P, Czekajło A et al. (2012) Epidemiological data on osteoporosis in women from the RAC-OST-POL Study. J Clin Densitom 15, 308-314.
18. World Health Organization (2004) Scientific Group on the Assessment of Osteoporosis at Primary Health Care Level. Summary meeting report - Brussels, Belgium, 5-7 May 2004. Geneva: WHO.

19. Kunachowicz H, Nadolna J, Przygoda B et al. (2005) Food Composition Tables. Warsaw: PZWL (in Polish).

20. Khan NC, Mai le B, Hien VT et al. (2008) Development and validation of food frequency questionnaire to assess calcium intake in postmenopausal Vietnamese women. J Nutr Sci Vitaminol 54, 124-129.

21. Uenishi K, Ishida H \& Nakamura K (2008) Development of a simple food frequency questionnaire to estimate intakes of calcium and other nutrients for the prevention and management of osteoporosis. J Nutr Sci Vitaminol 54, 25-29.

22. Hacker-Thompson A, Robertson TP \& Sellmeyer DE (2009) Validation of two food frequency questionnaires for dietary calcium assessment. J Am Diet Assoc 109, 1237-1240.

23. Pereira GA, Genaro PS, Santos LC et al. (2009) Validation of a food frequency questionnaire for women with osteoporosis. J Nutr Health Aging 13, 403-407.

24. Szymelfejnik EJ, Wądołowska L, Cichon R et al. (2006) Dairy products frequency questionnaire (ADOS-Ca) calibration for calcium intake evaluation. Pol J Food Nutr Sci 15, 229-236.

25. Central Statistical Office (2010) 2010 Statistical Yearbook. Warsaw: Central Statistical Office (in Polish).

26. Fardellone P, Cotté FE, Roux C et al. (2010) Calcium intake and the risk of osteoporosis and fractures in French women. Joint Bone Spine 77, 154-158.

27. Manios Y, Moschonis G, Panagiotakos DB et al. (2009) Changes in biochemical indices of bone metabolism in post-menopausal women following a dietary intervention with fortified dairy products. J Hum Nutr Diet 22, 156-165.

28. Zhong Y, Okoro CA \& Balluz LS (2009) Association of total calcium and dietary protein intakes with fracture risk in postmenopausal women: the 1999-2002 National Health and Nutrition Examination Survey (NHANES). Nutrition 25, 647-654.

29. Daly RM, Brown M, Bass S et al. (2006) Calcium- and vitamin $\mathrm{D}_{3}$-fortified milk reduces bone loss at clinically relevant skeletal sites in older men: a 2-year randomized controlled trial. J Bone Miner Res 21, 397-405.

30. Park H-M, Heo J \& Park Y (2011) Calcium from plant sources is beneficial to lowering the risk of osteoporosis in postmenopausal Korean women. Nutr Res 31, 27-31.

31. Tseng YH, Huang KC, Liu ML et al. (2009) Association between metabolic syndrome (MS) and bone mineral loss: a cross-sectional study in Puli Township in Taiwan. Arch Gerontol Geriatr 49, Suppl. 2, S37-S40.

32. Riedt CS, Cifuentes M, Stahl T et al. (2005) Overweight postmenopausal women lose bone with moderate weight reduction and $1 \mathrm{~g}$ /day calcium intake. J Bone Miner Res 20, 455-463.

33. Burge R, Dawson-Hughes B, Solomon DH et al. (2007) Incidence and economic burden of osteoporosis-related fractures in the United States, 2005-2025. J Bone Miner Res 22, 465-475.

34. Yaegashi Y, Onoda T, Tanno K et al. (2008) Association of hip fracture incidence and intake of calcium, magnesium, vitamin D, and vitamin K. Eur J Epidemiol 23, 219-225.

35. Lin YC, Chiu JF, Lin MC et al. (2005) Bone health status of the elderly in Taiwan by quantitative ultrasound. Asia Pac J Clin Nutr 14, 270-277.

36. Bruyere O, De Cock C, Mottet C et al. (2009) Low dietary calcium in European postmenopausal osteoporotic women. Public Health Nutr 12, 111-114.

37. Pongchaiyakul C, Kosulwat V, Charoenkiatkul S et al. (2008) The association of dietary calcium, bone mineral density and biochemical bone turnover markers in rural Thai women. J Med Assoc Thai 91, 295-302. 
38. Miura S, Nakamori M, Yagi M et al. (2009) Daily calcium intake and physical activity status in urban women living on low incomes in Davao, Philippines: a primary study for osteoporosis prevention. J Med Invest 56, 130-135.

39. Kumar A, Mittal S, Orito S et al. (2010) Impact of dietary intake, education, and physical activity on bone mineral density among North Indian women. J Bone Miner Metab 28, 192-201.

40. North American Menopause Society (2001) The role of calcium in peri- and postmenopausal women: consensus opinion of the North American Menopause Society Menopause. Menopause 8, 84-95.

41. Seidel D, Brayne C \& Jagger C (2011) Limitations in physical functioning among older people as a predictor of subsequent disability in instrumental activities of daily living. Age Ageing 40, 463-469.

42. Locker D (2002) Changes in chewing ability with ageing: a 7-year study of older adults. J Oral Rehabil 29, 1021-1029.
43. Mullie P, Godderis L \& Clarys P (2011) Determinants and nutritional implications associated with low-fat food consumption. Appetite 58, 34-38.

44. Napoli N, Thompson J, Civitelli R et al. (2007) Effects of dietary calcium compared with calcium supplements on estrogen metabolism and bone mineral density. Am J Clin Nutr 85, 1428-1433.

45. Farrell VA, Harris M, Lohman TG et al. (2009) Comparison between dietary assessment methods for determining associations between nutrient intakes and bone mineral density in postmenopausal women. J Am Diet Assoc 109, 899-904.

46. Uenishi K \& Yamaura T (2010) Nutrition and bone health lactose and bone. Clin Calcium 20, 424-429.

47. Nguyen TV, Center JR \& Eisman JA (2000) Osteoporosis in elderly men and women: effects of dietary calcium, physical activity, and body mass index. $J$ Bone Miner Res 15, 322-331. 